\title{
Zosteriform Cutaneous Distant Metastases as Onset of Relapsing Melanoma
}

\author{
Daniel Morgado-Carrasco, ${ }^{1}$ Clara Fernández-Sartorio, ${ }^{1}$ Cristina Carrera ${ }^{1}$
}

1 Melanoma Unit, Department of Dermatology, Hospital Clínic de Barcelona, Universitat de Barcelona, and Centro de Investigaciones en Red de Enfermedades Raras (CIBERER), Instituto de Salud Carlos III, Spain

Key words: melanoma, zosteriform metastases, cutaneous metastases, melanoma metastases

Citation: Morgado-Carrasco D, Fernández-Sartorio C, Carrera C. Zosteriform cutaneous distant metastases as onset of relapsing melanoma. Dermatol Pract Concept. 2020;10(1):e2020007. DOI: https://doi.org/10.5826/dpc.1001a07

Accepted: September 13, 2019; Published: December 31, 2019

Copyright: $@ 2019$ Morgado-Carrasco et al. This is an open-access article distributed under the terms of the Creative Commons Attribution License, which permits unrestricted use, distribution, and reproduction in any medium, provided the original author and source are credited.

Funding: None.

Competing interests: The authors have no conflicts of interest to disclose.

Authorship: All authors have contributed significantly to this publication.

Corresponding author: Cristina Carrera, MD, PhD, Melanoma Unit, Department of Dermatology, Hospital Clínic de Barcelona, Barcelona, Spain.Email: ccarrera@clinic.cat

\section{Case Presentation}

A 66-year-old man with a history of an ulcerated melanoma on the lumbar region, Breslow index $2.9 \mathrm{~mm}$, with regional lymph node involvement, presented with pinkish papules on his forehead 5 months after the initial surgery. The lesions rapidly evolved into multiple coalescent papulonodules forming a zosteriform plaque on his forehead (Figure 1). Skin biopsy confirmed the diagnosis of cutaneous melanoma metastases.

\section{Teaching Point}

Zosteriform metastases are rare, with only about 60 cases reported, and melanoma is one of the most frequent neoplasms implicated [1,2]. Physicians should suspect this infrequent form of skin metastases even when lesions are distant from the primary site.

\section{References}

1. Savoia P, Fava P, Deboli T, Quaglino P, Bernengo MG. Zosteriform cutaneous metastases: a literature meta-analysis and a clinical



Figure 1. Metastatic melanoma. Multiple coalescent papulonodules forming a zosteriform plaque on the forehead.

report of three melanoma cases. Dermatol Surg. 2009;35(9):13551363.

2. Chaudhary S, Bansal C, Husain A. Literature meta-analysis of zosteriform cutaneous metastases from melanoma and a clinico-histopathological report from India. Ecancermedicalscience. 2013;7:324. 